\title{
7 \\ Knowledge as Achievement, More or Less
}

\author{
John Turri
}

This essay enhances and extends a powerful and promising research program, performance-based epistemology, which stands at the crossroads of many important currents in contemporary epistemology, including the value problem, epistemic normativity, virtue epistemology, and the nature of knowledge. Performance-based epistemology offers at least three outstanding benefits: it explains knowledge's distinctive value, it places epistemic evaluation into a familiar and ubiquitous pattern of evaluation, and it solves the Gettier problem. But extant versions of performance-based epistemology have attracted serious criticism. This essay shows how to meet the objections without sacrificing the aforementioned benefits.

The essay proceeds as follows. Section 1 introduces the basic model of performance assessment. Section 2 introduces the leading version of performance-based epistemology, the achievement account of knowledge. Section 3 considers the objection that the achievement account is too weak, and shows how to strengthen it. Section 4 considers the objection that the achievement account is too strong, and shows how to weaken it. Section 5 shows how to adjust performance-based epistemology if it turns out that knowledge doesn't require truth. Section 6 briefly concludes.

\section{A Basic Model of Performance Assessment}

A raging Achilles leads the Greek charge, driving the Trojans all the way to the Scaean gate. The siege of Troy might have ended this day, but for one fateful shot. The Trojan prince Paris, perched in the tower high above the gate, places an arrow on his bow, surveys the bloody chaos below, identifies the indomitable Greek hero, takes aim and lets the shot fly. Apollo guides the arrow through the mass of bodies and trampling feet to bury deep into Achilles's ankle, just below his leg armor. Only in that very spot could Achilles receive his death blow. Blood gushing, strength failing, eyes dimming, Achilles staggers forward in one last feeble defiant gesture before toppling dead to the ground. 
We might assess Paris's shot along any number of dimensions. We might think it cowardly that he assailed Achilles from afar. Or we might think it foolish to shoot from the tower rather than help rally flagging Trojan spirits down at the gate, or unwise to shoot at the nearly invincible Achilles rather a more vulnerable Greek soldier. But setting aside such evaluation that places Paris's shot in a broader critical context, be it moral, political, or strategic, we can assess it more narrowly as an archery shot in battle, as a martial shot qua shot.

First, we might assess whether it attained its aim, that is, hit its target, Achilles's vulnerable heel. Here it scores perfectly. In virtue of this, call it accurate.

Second, we might assess it for skillfulness, that is, whether it manifests relevant archery skill or competence. Here our myth-makers omit the pertinent detail, so we may feel free to add details as we like. The son of a wealthy and powerful king, Paris no doubt received expert training. He also had a decade of experience with the bow in battle, warding off Greek invaders. So let's say his shot manifested competence. In virtue of this, call it adroit.

Third, we might assess whether it was accurate because it was competent. Here again our myth-makers are silent, so let's add some detail. Apollo had orders from Zeus to: guide the arrow into Achilles's ankle just in case, and precisely because, Paris shoots competently. Thus Paris's display of competence figures crucially in explaining why the shot is accurate. His shot is accurate because competent. In virtue of this, call it apt.

Fourth, we might assess whether the shot's outcome-the arrow's striking Achilles's heel-manifests Paris's competence. A competence is a special type of power or disposition, and we almost certainly cannot specify in general when an outcome manifests a disposition. But case by case we find it relatively easy to tell, and in this case the outcome clearly doesn't manifest Paris's competence. It manifests Apollo's competence at guiding the arrow's flight through the tangled and shifting mass of humanity. (Should that verdict not strike you as obviously correct, we can add that as the arrow flew, a Trojan chariot unexpectedly and improbably tumbled, interposing itself between the arrow and Achilles's heel, whereupon Apollo immediately altered the arrow's flight to compensate for the unforeseen obstacle.) As one modern teller of the tale puts it, "Apollo," not Paris, "killed Achilles." In virtue of this, Paris's shot fails to be adept. Had the outcome manifested his competence, the shot would have been adept.

Ernest Sosa (2007) introduced the triple-A performance-assessment structure of accuracy, adroitness, and aptness. Accurate performances achieve their aim, adroit performances manifest competence, and apt performances are accurate because adroit. To that I add the fourth category, adeptness. ${ }^{2}$ An adept performance is one

${ }^{1}$ Davidson (2008). Davidson recounts a different version of Achilles's death, which the medievals attributed to the ancient Trojan cleric Dares Phrygius, wherein Achilles dies in an Apollonian temple after killing Troilus and Hector. But the central point remains the same in that version, namely: Apollo guides Paris's shot into Achilles's heel. My version of Achilles's death hews closer to Rosemary Sutcliff's (1993) retelling.

2 All of these statuses are a matter of degree, but the details needn't detain us here. Sosa might intend 'aptness' to name what I call 'adeptness', though the official characterization falls short of it. In any event, we might want a name for aptness as described in the text. 
whose accuracy manifests competence (as opposed to being accurate merely because competent). Call an adept performance's outcome an achievement.

In a narrow sense, any accurate performance succeeds, be the outcome good, bad, or indifferent. The assassin succeeds if he fatally wounds the victim, though he deserves no plaudits, only condemnation, for this deplorable outcome. The despotic cabal succeeds if its activities establish a despotism, another deplorable outcome. Labeling some performance a 'success' here means only that it is accurate. ${ }^{3}$ It implies no approval of either the aim, outcome, or activity. Similarly, labeling some performance or outcome an 'achievement' doesn't imply approval. Many achievements ought never have come to pass. (If such positive connotations unfailingly accompany 'achievement' in your idiolect, please substitute whichever works best of 'feat' or 'deed'.) Consistent with those general cautionary points about the relation between success, achievement, and approval, some types of success or achievement might be inherently good (or bad), and recognizing them as such would imply that they merit approval (or disapproval).

\section{The Achievement Account of Knowledge}

On one influential contemporary view, we best understand knowledge as a cognitive achievement (Sosa 2007, Riggs 2009, Zagzebski 2009, Greco 2010). This view treats belief-formation as a cognitive performance whose aim is truth. Accurate beliefs are true. Adroit beliefs manifest cognitive competence, including discriminating perception, cogent reasoning, and good memory. Apt beliefs are true because competent. Finally, your belief that $\mathrm{Q}$ is adept just in case your truly believing $\mathrm{Q}$ manifests your cognitive competence. Adept beliefs are cognitive achievements and are identified with knowledge. Call this the achievement account of knowledge, or AA for short (pronounced "double A").

AA promises at least three outstanding benefits. First, it helps explain the added value of knowledge over mere true belief, a question which has been central to epistemology ever since Plato’s Meno (Riggs 2002, Kvanvig 2003, Zagzebski 2003, Pritchard and Turri 2011). We value achievement over mere success, at least when the relevant outcome is unobjectionable or better. For instance, compare a novel whose enthralling plot manifests the author's literary genius to a novel whose enthralling plot is due to a monkey randomly striking a keyboard repeatedly. We value the former more than the latter. Or compare a dance whose visual beauty manifests the dancer's skill to a dance whose visual beauty is due to a series of fortuitous stumbles. The former is better than the latter. Likewise, compare a stretch of inquiry whose eventual true conclusion manifests the inquirer's intellectual skill to one whose true conclusion is due to a series of lucky guesses. The former is better than the latter.

\footnotetext{
${ }^{3}$ Distinguish this from the performance's succeeding in any of the broader senses mentioned earlier, or satisfying any ulterior aims the agent has in performing. Failing in the narrow sense might be best overall or best serve the agent. For instance, she might engage her enemy in a game of chess to distract him, which goal is best served by playing poorly and setting herself up to be easily checkmated. The outcome is a chess-failure yet, relative to the agent's own goals, a smashing success.
} 
Second, AA places epistemic evaluation in a familiar pattern (Sosa 2007, Greco 2007a: 57-8; see also Turri 2006, 2010, 2011c, 2011d, and Turri under Whether it's art, athletics, oratory, or inquiry, we're keen to assess how outcomes relate to the relevant skills and abilities. The basic model of performance assessment applies across the entire range of evaluable rational activity. Knowledge takes its place as an intellectual achievement, fundamentally similar to artistic, athletic, political, and other sorts of achievement.

Third, AA solves the Gettier problem. ${ }^{4}$ Consider this standard Gettier case.

(HUSBAND) Mary enters the house and looks into the living room. A familiar appearance greets her from her husband's chair. She thinks, "My husband is sitting in the living room," and then walks into the den. But Mary misidentified the man in the chair. It's not her husband, but his brother, whom she had no reason to think was even in the country. However, her husband was seated along the opposite wall of the living room, out of Mary's sight, dozing in a different chair. (Adapted from Zagzebski 1996: 285-6)

HUSBAND follows the standard recipe for generating Gettier cases. Start with a belief sufficiently justified to meet the justification requirement for knowledge. Then add an element of bad luck that would normally prevent the justified belief from being true. Lastly add a dose of good luck that "cancels out the bad," so the belief ends up true anyhow. It has proven difficult to explain why this "double luck" prevents knowledge (Zagzebski 1994). AA diagnoses the problem as follows. The outcome-in this case, Mary's true belief that her husband is home-doesn't manifest Mary's intellectual skills, so Mary doesn't know that her husband is home. This verdict fits seamlessly into a more general pattern of manifestation failure, wherein the relevant outcome fails to manifest the relevant power or ability (Turri 2011a, 2012a, 2013).

I emphasize that this is not the place to argue at length that AA delivers on these benefits, a task accomplished in numerous venues by many theorists over the last decade and more. For present purposes, I assume that AA does deliver on those benefits. I've explained the basic reasons for thinking that it does, so we can later appreciate how the alternative versions of performance-based epistemology, introduced over the next couple sections, can likewise deliver on those benefits, while avoiding objections that plague AA.

\section{The Ample Achievement Account of Knowledge}

Duncan Pritchard (2008: 445-6) rejects AA, arguing that cognitive achievement does not suffice for knowledge. Achievements can be unsafe. But knowledge cannot be unsafe. So knowledge is not (essentially) an achievement. ${ }^{5}$

\footnotetext{
${ }^{4}$ Recent empirical work on Gettier cases should is $\square$ our view of what exactly the Gettier problem amounts to and what the best solution to it is. For $~ e, ~ s e e$ Starmans and Friedman (2012); Turri (2013); Nagel et al. (forthcoming); Turri, Buckwalter, and Blouw (forthcoming); Blouw, Buckwalter, and Turri (forthcoming).

${ }^{5}$ Says Pritchard (2008: 445), "knowledge seems to be intolerant to luck in a way [that] achievements are not ... " Pritchard pairs this objection with another, arguing, following Lackey (2007), that achievement is
} 
Suppose a performance succeeds. We can ask how easily it might have failed. If the correct answer is 'not easily', then the performance is safe. More generally, a performance is safe just in case it (i) succeeds and (ii) not easily would have failed. A belief is safe just in case it (i) is true and (ii) not easily would have been false. ${ }^{6}$

To appreciate Pritchard's critique, let's start by considering this case:

(FORCE FIELD) Fielding is participating in an archery competition. He selects one target out of hundreds to shoot at. Fielding is focused, the wind perfectly still. He nocks the arrow, assumes his stance, takes aim and skillfully releases the shot, which glides unerringly into the heart of the stationary target. Bulls-eye. (Adapted from Pritchard 2008: 445)

This counts as an achievement. Adding the following details does not disrupt the intuition:

(FORCE FIELD cont'd) Fielding had randomly selected the only target on the range lacking a hidden force-field apt to repel any incoming arrow.

Pritchard concludes that Fielding's bullseye is an achievement despite being "clearly lucky, in the sense that [he] could very easily have" missed (Pritchard 2008: 445).

Pritchard then compares FORCE FIELD to,

(BARN) Henry and his son are driving through the country. Henry pulls over to stretch his legs, and while doing so regales his son with a list of currently visible roadside items. "That's a tractor. That's a combine. That's a horse. That's a silo. And that's a fine barn," Henry added, pointing to the nearby roadside barn. It was indeed a fine barn Henry saw. But unbeknownst to them the locals recently secretly replaced nearly every barn in the county with fake barns. Henry happens to see the one real barn in the whole county. But had he instead set eyes on any of the numerous nearby fakes, he would have falsely believed it was a barn. (Adapted from Goldman 1976: 172-3)

Pritchard notes that BARN exhibits the same structure as FORCE FIELD, so consistency requires us to count Henry's true belief as an achievement too. But Henry's belief doesn't count as knowledge. More generally, adept beliefs can be unsafe whereas knowledge cannot, ruining the identification of knowledge with adept belief.

AA's proponents can respond in at least three ways. First, they might argue that Henry does indeed know, so the disanalogy dissipates (Turri 2011a, 2012a; Turri, Buckwalter, and Blouw 2015; Blouw, Buckwalter, and Turri, forthcoming). I think this response reflects the way we ordinarily view knowledge and is, moreover, correct upon reflection, but I will grant for the sake of argument that Henry doesn't know. Second, they could argue that whereas other achievements can be unsafe, knowledge cannot. While not obviously implausible-knowledge might just be special in this way-this

not necessary for knowledge either. But this latter worry has been repeatedly adequately addressed elsewhere (see Greco 2007a, Riggs 2009, and Turri 2011a).

6 "Possible worlds" terminology provides a convenient intuitive gloss on 'not easily'. In this idiom, it's true that some event would not easily occur (in certain conditions) just in case, at all or most nearby worlds (where those conditions obtain), it does not occur. Here I don't commit myself to the adequacy of this idiom. 
response runs the risk of appearing ad hoc. Better would be, third, to identify a class of achievements that must be safe and contend that knowledge patterns with these. This deviates from AA but still identifies knowledge with a type of achievement. I will now develop this third response.

Begin with a natural extension to our theory of performance-assessment. Performances have a quintuple-A structure. Add amplitude to the four previously mentioned. A performance is ample just in case its safety (not just its accuracy) manifests the agent's competence. ${ }^{7}$ Your belief is ample just in case its safety (not just its truth) manifests your competence. Ample performances form a proper subset of adept performances. Call the outcome of an ample performance an ample achievement, and call the view that knowledge is ample belief the ample achievement account of knowledge or $A A+$ for short (pronounced "double A plus").

(Let's define a further property—call it supersafety — that a performance has just in case it (i) succeeds and (ii) couldn't have failed. In line with the current suggestion, we might add that a performance is adamantine just in case its supersafety (not just its safety) manifests the agent's skill. It's noteworthy that the underlying performance-based model extends to accommodate the ultra-Cartesian view that knowledge is adamantine belief. In unpublished work, Ernest Sosa proposes a fascinating reading of Descartes along these very lines. Many statuses betwixt safety and supersafety are possible.)

$\mathrm{AA}+$ shares the benefits of AA. First, AA+ can explain the added value of knowledge over mere true belief. We value ample achievement over mere success, at least when the relevant outcome is unobjectionable or better. Second, it places epistemic evaluation in a familiar pattern, that of ample achievement. Compare adversarial competition. In line with our theory of performance-assessment, when victory is the outcome, we may ask how it relates to the agent's performance. Victory manifesting your skill counts as an achievement. But not every victory is an overwhelming victory, which can also be an outcome of competition. To overwhelm an opponent, you must not only succeed, but do so by a wide margin, as was the case with Usain Bolt's crushing victories in the men's 100- and 200-meter sprints at the 2008 Olympics. (Compare that to when Michael Phelps won the men's 100-meter butterfly by one-hundredth of one second over Milorad Cavic at the 2008 Olympics.) An advocate of this third response, then, might liken knowledge to overwhelming a fact. Third, AA+ solves the Gettier problem exactly the same way as AA, namely, by pointing out that the relevant outcome fails to manifest the agent's relevant ability.

\section{The Attainment Account of Knowledge}

The last section entertained the objection that cognitive achievement isn't sufficient for knowledge. This section entertains the objection that it isn't necessary for knowledge.

\footnotetext{
${ }^{7}$ Greco (2007b) might advocate this type of response when he suggests that knowledge requires "agentbased safety." He doesn't explain what agent-based safety is.
} 
Start by noticing something I didn't emphasize earlier in section 3. AA's proponents claim that knowledge is an achievement that proceeds from select intellectual dispositions. Sosa (2007: 29) says knowledge must be produced by a competence, which is a disposition "that would in appropriately normal conditions ensure (or make highly likely) the success of any relevant performance issued by it." Greco (2002: 308) identifies knowledge as true belief manifesting "reliable cognitive abilities or powers." Linda Zagzebski (1996: II.4.1.2 and III.2) identifies knowledge as true belief manifesting intellectual virtue, where a virtue is an entrenched character trait enabling "reliable success." To settle on convenient terminology, I'll say these theorists claim that knowledge-producing dispositions must be normally successful.

(As I use the term here, 'disposition' denotes the genus that includes as species abilities, from the maximally reliable down to the extremely weak. Weak abilities are unreliable but not completely useless. I understand competences, skills, powers, excellences, etc., as types of ability.)

Here we encounter a potential problem for AA. Achievement does not generally require normally successful dispositions. Ted Williams is the best baseball hitter ever. At least often when he got a hit, he performed adeptly. But he normally failed to get a hit: the relevant ability could at best be counted on to produce a hit about four in ten times (his best yearly average ever was .407). And many lesser hitters sometimes perform adeptly too, despite normally failing seventy-five percent of the time or more. No disposition that normally fails is normally successful.

Consider also this case.

(BABY STEPS) Geno is eleven months old. He's daily been gaining confidence in his ability to balance on two feet. Today he stood holding onto the couch when an object in Dad's hand commanded his attention. Inspired, Geno let go and, to his parents' delight, took his first two steps in Dad's direction.

Those first steps were an achievement. They manifested Geno's blossoming bipedalism. But of course he's still a highly unreliable walker. (At least, he was unreliable when those first steps occurred.) So achievement can issue from even highly unreliable ability.

Baby steps are not unique. Achievements populate the road to proficiency in many spheres. A child's first grammatical sentence manifests her incipient linguistic ability. A rookie golfer's first par manifests his incipient putting skill. A pleasing chord manifests a novice musician's incipient musical ability. An undergraduate's essay might even manifest incipient compositional skill. Even though their authors could not reliably produce such results, that first sentence, first par, first pleasing chord, and first thoroughly grammatical essay are achievements (the last of which is unfortunately far too rare).

Reflection shows that this result is expected. Outcomes often manifest unreliable dispositions in mundane cases. A car's starting might manifest an unreliable starter's power. A room's being illuminated might manifest an unreliable flashlight's power. 
A candle's burning might manifest an unreliable lighter's power. A door's opening might manifest an unreliable sensor's power. Such outcomes are possible even if unexpected from unreliable items.

This raises a question for AA (Turri 2012b). If achievements don't generally require normally successful dispositions, then why insist that knowledge must proceed from normally successful dispositions? Does not that restriction threaten to rule out too much?

But wait. We've seen that success can manifest unreliable ability. I called those outcomes "achievements," said that "achievements" populate the road to proficiency in many spheres, and posed the challenge to AA in terms of "achievements." Yet given the way we earlier characterized 'achievement', AA's proponents might object. You perform adeptly just in case the successful outcome manifests your competence. Competence requires more than weak, unreliable ability. (The same goes for other categories AA theorists tend to favor, such as excellence and virtue.) This fair point forces me to reformulate the question, which I'll now do.

We first need a term for performances whose success manifests reliable or unreliable abilities. Call such a performance adequate. All adept performances are adequate, but not vice versa. We also associated 'achievement' with the outcome of adept performance. We need a term for the outcome of adequate performance. Call them attainments. All achievements are attainments, but not vice versa. Call attainment that is not also an achievement a mere attainment. Finally, call the view that identifies knowledge with intellectual attainment the attainment account of knowledge or $A A$ - for short (pronounced "double A minus").

Now let's reformulate our question. Why identify knowledge with intellectual achievement rather than attainment? Why prefer AA over AA-? Why exclude mere intellectual attainments? What's wrong with an intellectual performance as adequate as a typical Ted-Williams double?

These are important questions, which AA's proponents ought to have answers to. But for present purposes, I want to concentrate on something else: even if it turns out that AA- is preferable, we're still left with a version of performance-based epistemology that delivers on all three benefits mentioned earlier. First, AA- can explain the added value of knowledge over true belief. We value attainment over mere success, at least when the relevant outcome is unobjectionable or better. Second, AA- places epistemic evaluation in a familiar pattern, namely, that of attainment. Third, AA- can solve the Gettier problem the same way AA does, by pointing out that the relevant outcome fails to manifest the relevant disposition.

\section{Knowledge and Truth}

Suppose you think it is possible to know false things. You think that even if Q is false, it's still possible to know Q, so long as it is approximately true. So you'll think that AA is too strong, but not for the same reason as proponents of AA-. To accommodate this 
intuition, we need only adjust the admissible outcomes. Call a performance that fails but nearly succeeds approximate. Call an approximate performance's outcome an approximation. Now we can simply append a disjunct to one of the earlier definitions of knowledge. You know Q just in case your believing Q is either an achievement (attainment) or an approximation. ${ }^{8}$ Call this the approximation (or better) account of knowledge.

Or suppose you think that knowledge doesn't even require approximate truth. Rather, you think completely false beliefs can be knowledge, so long as they're reliably produced. ${ }^{9}$ Performance-based epistemology can accommodate this intuition as well. Adroit beliefs manifest competence, and competence must be reliable. But adroit beliefs can be false. So we can understand knowledge as adroit belief. Call this the adroit-belief account of knowledge.

\section{Conclusion}

Further variations on the basic theme are possible. But I've said enough to clarify how to manipulate the model. You can strengthen or weaken the admissible outcomes. ${ }^{10} \mathrm{Or}$ you can strengthen or weaken the admissible dispositions. Or you can even adjust both. The relation of manifestation is common to all variants. Performance-based epistemology is a substantive, powerful, and versatile approach. The objections to AA canvassed here shouldn't convince us to abandon performance-based epistemology and its considerable benefits just yet. To do so would be to throw the proverbial baby out with the bath water. ${ }^{11}$

\footnotetext{
${ }^{8}$ More fully spelled out: you know Q just in case either (a) your truly believing Q manifests your cognitive competence (ability) or (b) your approximating Q manifests your cognitive competence (ability).

9 Again, recent empirical work should inform theoretical work on this question, at least to the extent that the theoretical work purports to describe knowledge ordinarily understood. See Buckwalter forthcoming; Buckwalter and Turri under review. See also Hazlett 2010, Turri 2011b, and Hazlett 2012.

${ }^{10}$ One objection not considered here is that knowledge doesn't require belief, in which case the domain of admissible outcomes must include some other sort of representational state or cognitive pro-attitude. Going back to Radford (1966), some contemporary philosophers have questioned whether knowledge entails belief. Recent experimental work has re-ignited that old theoretical debate (Myers-Schulz and Schwitzgebel 2013; Murray et al. 2013), suggesting that knowledge ordinarily understood does not require belief. However, further empirical work has uncovered important nuances in the folk psychology of belief, and the balance of evidence seems to support the view that knowledge ordinarily understood does require belief in one form or another (see Rose and Schaffer forthcoming; Buckwalter, Rose and Turri 2013; Turri and Buckwalter, under review; Rose, Buckwalter, and Turri 2014). Thus it seems that the envisioned objection to the performance-based approach can be overcome.

11 This research was kindly supported by the Social Sciences and Humanities Research Council of Canada, The Character Project at Wake Forest University and the John Templeton Foundation (neither of which necessarily endorses any opinion expressed here), and an Ontario Early Researcher Award.
} 


\section{References}

Blouw, P., W. Buckwalter, and J. Turri, forthcoming. “Gettier Cases: A Taxonomy.” In R. Borges, C. de Almeida, and P. Klein (eds) Explaining Knowledge: New Essays on the Gettier Problem. Oxford: Oxford University Press.

Buckwalter, W., forthcoming. "Factive Verbs and Protagonist Projection." Episteme.

Buckwalter, W., D. Rose, and J. Turri 2013. "Belief through Thick and Thin.” Noûs: 1-28. doi:10.1111/nous.12048.

Buckwalter, W., and J. Turri, under review. "In the Thick of Moral Motivation." University of Waterloo.

Davidson, J., 2008. “Troilus and the Death of Achilles." Guardian (London), 17 January. Part of "The Greek Myths" series.

Greco, J., 2002. "Virtues in Epistemology." In Paul Moser (ed.) The Oxford Handbook of Epistemology, 287-315. Oxford: Oxford University Press.

Greco, J., 2007a. "The Nature of Ability and the Purpose of Knowledge." Philosophical Issues 17: $57-69$.

Greco, J., 2007b. “Worries about Pritchard’s Safety." Synthese 158: 299-302.

Greco, J., 2010. Achieving Knowledge. Cambridge: Cambridge University Press.

Hazlett, A., 2010. "The Myth of Factive Verbs." Philosophy and Phenomenological Research 80(3): 497-522.

Hazlett, A., 2012. "Factive Presupposition and the Truth Condition on Knowledge." Acta Analytica 27(4): 461-78.

Kvanvig, J. L., 2003. The Value of Truth and the Pursuit of Understanding. Cambridge: Cambridge University Press.

Lackey, J., 2007. "Why We Don't Deserve Credit for Everything We Know." Synthese 158: 345-61.

Murray, D., J. Sytsma, and J. Livengood, 2013. "God Knows (But Does God Believe?)." Philosophical Studies 166(1): 83-107.

Myers-Schulz, B., and E. Schwitzgebel, 2013. "Knowing that P Without Believing that P." Noûs. 47(2): 371-84.

Nagel, J., V. San Juan, and R. A. Mar, forthcoming. "Lay Denial of Knowledge for Justified True Beliefs." Cognition.

Pritchard, D., 2008. “Greco on Knowledge: Virtues, Contexts, and Achievements." Philosophical Quarterly 58 (232): 437-47.

Pritchard, D. and J. Turri 2011. “The Value of Knowledge." Stanford Encyclopedia of Philosophy (Nov. 2011) <http://plato.stanford.edu/entries/knowledge-value> accessed July 7, 2015.

Radford, C., 1966. "Knowledge-By Examples." Analysis 27: 1-11.

Riggs, W., 2002. "Reliability and the Value of Knowledge." Philosophy and Phenomenological Research 64(1): 79-96.

Riggs, W., 2009. “Two Problems of Easy Credit." Synthese 169(1): 201-16.

Rose, D., and J. Schaffer, forthcoming. "Knowledge Entails Dispositional Belief." Philosophical Studies.

Rose, D., W. Buckwalter, and J. Turri 2014. "When Words Speak Louder than Actions: Delusion, Belief and the Power of Assertion." Australasian Journal of Philosophy 92(4): 683-700.

Sosa, E., 2007. A Virtue Epistemology: Apt Belief and Reflective Knowledge, i. Oxford: Oxford University Press. 
Starmans, C., and O. Friedman 2012. "The Folk Conception of Knowledge." Cognition 124(3): $272-83$.

Sutcliff, R., 1993. Black Ships before Troy: The Story of The Iliad. New York: Laurel-Leaf.

Turri, J., 2006. "Epistemic Reasons." PhD dissertation, Brown University.

Turri, J., 2010. "On the Relationship Between Propositional and Doxastic Justification." Philosophy and Phenomenological Research 80(2): 312-26.

Turri, J., 2011a. "Manifest Failure: The Gettier Problem Solved." Philosophers' Imprint 11(8): $1-11$.

Turri, J., 2011b. "Mythology of the Factive." Logos \& Episteme 2(1): 143-52.

Turri, J., 2011c. "Believing for a Reason." Erkenntnis 74(3): 383-97.

Turri, J., 2011d. "The Express Knowledge Account of Assertion." Australasian Journal of Philosophy 89(1): 37-45.

Turri, J., 2012a. “Is Knowledge Justified True Belief?” Synthese 184(3): 247-59.

Turri, J., 2012b. Review of John Greco, Achieving Knowledge: A Virtue-Theoretic Account of Epistemic Normativity. Mind 121(481): 183-7.

Turri, J., 2013. "A Conspicuous Art: Putting Gettier to the Test." Philosophers' Imprint 13(10): $1-16$.

Turri, J., forthcoming. "Sustaining Rules: A Model and Application." In J. A. Carter, E. C. Gordon, and B. Jarvis (eds) Knowledge First. Oxford: Oxford University Press.

Turri, J., and W. Buckwalter, under review. "Descartes's Schism, Locke's Reunion: Completing the Pragmatic Turn in Epistemology."

Turri, J., W. Buckwalter, and P. Blouw, 2015. "Knowledge and Luck." Psychonomic Bulletin \& Review 22(2): 378-90.

Zagzebski, L., 1994. “The Inescapability of Gettier Problems.” Philosophical Quarterly 44(174): 65-73.

Zagzebski, L., 1996. Virtues of the Mind: An Inquiry into the Nature of Virtue and the Ethical Foundations of Knowledge. Cambridge: Cambridge University Press.

Zagzebski, L., 2003. “The Search for the Source of Epistemic Good.” Metaphilosophy 34: 12-28.

Zagzebski, L., 2009. On Epistemology. Belmont, CA: Wadsworth. 